Communication

\title{
A Validated HPLC Method for the Determination of Vanillyl Butyl Ether in Cosmetic Preparations
}

\author{
Francisco Ríos *, Antonio Alberola, Joaquin Melendez, Gema Muedra and Francisco Trigo \\ Suavizantes y Plastificantes Bituminosos S.L., Polígono Industrial de Cheste, vial 6, 46380 Cheste, Valencia, \\ Spain; antonio.alberola@spb.es (A.A.); joaquin.melendez@spb.es (J.M.); \\ gema.muedra@spb.es (G.M.); francisco.trigo@spb.es (F.T.) \\ * Correspondence: francisco.rios@spb.es; Tel.: +34-962-512-085
}

Academic Editor: Enzo Berardesca

Received: 24 October 2016; Accepted: 4 February 2017; Published: 10 February 2017

\begin{abstract}
A specific HPLC (High-Performance Liquid Chromatography) method has been developed and validated for the determination of vanillyl butyl ether in cosmetic products. The extraction procedure with an isopropanol water 1:1 mixture is described. The method uses a RP-C-18 column with isocratic elution and an ultraviolet (UV) detector. The mobile phase consists of a mixture of acetonitrile and buffer $\left(\mathrm{Na}_{2} \mathrm{HPO}_{4} 20 \mathrm{mM}\right.$ in water) (30:70 v/v) with a variable flow rate. The method was validated with respect to accuracy, precision (repeatability and reproducibility), specificity and linearity. The procedure described here is simple, selective and reliable for routine quality control analysis and stability tests of commercially available cosmetic products.
\end{abstract}

Keywords: vanillyl butyl ether; HPLC; method validation; cosmetic product

\section{Introduction}

There are many instances when a cosmetic is required to provide a warming sensation and enhance blood circulation in a specific location. Whether it is to provide psychophysical relaxation, pain relief, fat burning sensation or lip plumping, topic application of a warming active ingredient is usually required. Substances known to impart a sensation of warmth upon application include capsicum (red pepper), ginger extract or benzyl nicotinate, amongst others. However, these products typically produce side-effects in the form of skin irritation, burning, itching and reddening of the skin [1]. Recently, vanillyl alcohol ether derivatives, and specifically vanillyl butyl ether, has been proposed as an alternative, milder warming agent for personal care applications [2-4].

Quality controls to determine precisely the concentration of the warming agent and its correct dispersion in the bulk formulation are required, to assess the correct dosage of the product before its launch on the market. Moreover, the method should not use complicated and labour-intensive pre-treatment procedures such as distillation, multiphase extractions, etc. if they have to be used routinely in industry based labs.

It is worthwhile noting that working with cosmetic products presents additional difficulties, due to the presence of many excipients/vehicles (fats, oils, waxes) which are typically present in a very high concentration relative to the active ingredients, further complicating the analytical process.

Therefore, the purpose of the present study was to develop and validate a simple, accurate and robust HPLC (High-Performance Liquid Chromatography) method for the determination of vanillyl butyl ether, suitable for the raw material as well as for cosmetics finished products.

The first part of the work was focused on the development of an extraction procedure to selectively pick up the vanillyl butyl ether from a complex mixture. The results of the proposed HPLC method were validated using a commercial tiger balm-like cosmetic product containing around $0.7 \%$ vanillyl butyl ether, with good extraction efficiency. 


\section{Materials and Methods}

Acetonitrile and Isopropanol used in this study were of HPLC grade (Scharlab, Barcelona, Spain). Vanillyl butyl ether (pure $>96 \%$ ) was purchased from Sigma Aldrich (St. Louis, MO, USA). Distilled water was deionized by using a Milli-Q system (Millipore, Bedford, MA, USA).

An Agilent Infinity 1200 HPLC system (Agilent Technologies, Singapore) equipped with an infinity LC (Liquid Chromatography) grad ALS (Autosampler) Heater was used. RP-HPLC was performed isocratically at $50{ }^{\circ} \mathrm{C}$ using a Zorbax Eclipse Plus C-18 $(150 \mathrm{~mm} \times 4.6 \mathrm{~mm}, 3.5 \mu \mathrm{m})$ column. The mobile phase consisted of a mixture of Acetonitrile/buffer $\left(20 \mathrm{mM} \mathrm{Na}_{2} \mathrm{HPO}_{4}\right.$ in deionized water, with $\mathrm{pH}$ adjusted to 1.8 with orthophosphoric acid $(85 \%))(30: 70, v / v)$. The flow rate was $1.5 \mathrm{~mL} / \mathrm{min}$ for the first $17 \mathrm{~min}$ and $4 \mathrm{~mL} / \mathrm{min}$ for the following $14 \mathrm{~min}$ until the end of the analysis. Injection volume was $10 \mu \mathrm{L}$. The eluent was monitored with an ultraviolet (UV) detector at $230 \mathrm{~nm}$.

\subsection{Method Development}

Initial trial experiments were conducted, in a view to select a suitable solvent system for the extraction of the vanillyl butyl ether. The suitability of the extraction mixture was decided on the basis of the time required for the extraction, ease of preparation and the use of readily available cost-effective solvents. These included acetonitrile-methanol (75:25, $v / v)$ acetonitrile-water $(70: 30, v / v)$ isopropanol-water $(60: 40, v / v)$ and isopropanol-water $(50: 50, v / v)$. The latter was found to be the optimum, based on extraction from the complex matrix.

\subsection{Method Validation}

The linearity test was performed using six different amounts of vanillyl butyl ether in the range $12-100 \mu \mathrm{g} / \mathrm{mL}$ from a stock solution $(5000 \mu \mathrm{g} / \mathrm{mL})$ in isopropanol:water $(50: 50, v / v)$. Dilutions were prepared in isopropanol:water $(50: 50, v / v)$ too. The data of peak area versus active component concentration was treated by linear least-square regression analysis.

Precision of the method was determined by repeatability (intra-day) and intermediate precision (inter-day variation). Repeatability was analyzed by examining 10 determinations of the same batch of standard material at a known concentration. The samples were stored at $10{ }^{\circ} \mathrm{C}$ for 15 days. Intermediate precision (interday variation) was studied by assaying ten samples containing a known amount of vanillyl butyl ether on different days. Solutions corresponding to each concentration level were injected in duplicate.

Accuracy is the measure of how close the experimental value is to the true value. For the recovery studies, a sample was prepared with a known added amount of pure Vanillyl butyl ether (Conc spiked) in a blank matrix of isopropanol:water (50:50, v/v). This solution was injected ten times, concentration was calculated (Conc $\mathrm{f}_{\text {found }}$ ) and percent recoveries were calculated using Equation (1):

$$
\text { Recovery }(\%)=\frac{\text { Conc }_{\text {found }}}{\text { Conc }_{\text {spiked }}} \cdot 100
$$

In order to validate the developed method, the limit of detection (LOD) and limit of quantification (LOQ) were calculated using a signal-to-noise ratio of 2:1 and 10:1, respectively.

Analysis of vanillyl butyl ether on marketed cosmetic products was performed on a commercial tiger balm-like product (balsamo oriental, Deliplus, Mercadona, Spain). The sample was analyzed after being extracted by the following method: in a glass flask, $0.5 \mathrm{~g}$ of sample was weighed out. An amount of $25 \mathrm{~g}$ of isopropanol:water $(50: 50, \mathrm{v} / \mathrm{v})$ were added for extraction by sonication at $50{ }^{\circ} \mathrm{C}$ for $5 \mathrm{~min}$. Following this period, the flask was placed in a fridge for $10 \mathrm{~min}$, allowing the Vaseline from the formulation to re-solidify. An amount of $10 \mathrm{~g}$ of that first dilution was transferred to a clean flask, and $20 \mathrm{~g}$ of isopropanol:water $(50: 50, v / v)$ was added. The resulting solution was filtered through a $0.45 \mu \mathrm{m}$ filter and analyzed by HPLC. 


\section{Results and Discussion}

The chromatographic separation of vanillyl butyl ether from the rest of the compounds in the commercial product was carried out in the isocratic mode, with a mixture of Acetonitrile/buffer $\left(20 \mathrm{mM} \mathrm{Na}_{2} \mathrm{HPO}_{4}\right.$ in deionized water) $(30: 70, v / v)$ as the mobile phase. Under the conditions described in the preceding section, the retention time for vanillyl butyl ether was $13.728 \pm 0.8 \mathrm{~min}$.

The column was equilibrated with the mobile phase flowing at $1.5 \mathrm{~mL} / \mathrm{min}$ for about $60 \mathrm{~min}$ prior to injection. The column temperature was maintained at $50^{\circ} \mathrm{C}$. Chromatograms of the resulting solutions gave excellent separation and resolution.

\subsection{Method Validation}

\subsubsection{Linearity}

The peak area versus vanillyl butyl ether concentration was plotted to construct a standard curve. The lineal regression for the calibration plots showed a good linear relationship with a coefficient of correlation of $r=0.9999$. The range of reliable quantification was set at $12-100 \mu \mathrm{g} / \mathrm{mL}$ as no significant difference was observed in the slope of the standard curve in this range. The linear regression data is indicative of a good linear relationship between the peak area and the concentration over a wide range. The correlation coefficient indicates high significance.

\subsubsection{Precision}

The \%RSD (Relative Standard Deviation) were found to be less than 0.67 and 0.73 for intra-day and inter-day precision respectively, indicating that the method is reliable and reproducible (Table 1). In addition, recovery percentage was found $98.5 \%$.

Table 1. Intra and Interday precision data of the analytical method for vanillyl butyl ether based on prepared and found concentrations (mean \pm \%RD (Relative Standard Deviation)) $(n=10)$.

\begin{tabular}{ccc}
\hline \multirow{2}{*}{$\begin{array}{c}\text { Prepared Concentration } \\
(\mu \mathrm{g} / \mathrm{mL})\end{array}$} & Intraday Analysis & Interday Analysis \\
\cline { 2 - 3 } & Found Conc. $(\mu \mathrm{g} / \mathrm{mL})$ & Found Conc. $(\mu \mathrm{g} / \mathrm{mL})$ \\
\hline & 76.93 & 78.52 \\
76.84 & 77.99 \\
76.43 & 77.77 \\
75 & 76.04 & 75.58 \\
& 75.75 & 76.31 \\
& 75.70 & 76.16 \\
& 76.56 & 76.77 \\
& 75.72 & 76.09 \\
& 76.68 & 76.45 \\
& 75.67 & 76.42 \\
\hline Mean \pm SD, RSD & $76.24 \pm 0.01,0.67$ & $76.76 \pm 0.01,0.73$ \\
\hline
\end{tabular}

\subsubsection{Accuracy}

For determining accuracy, a vanillyl butyl ether standard solution of known concentration was injected in 10 replicates, and the Student's $t$-test was used for acceptance. A tr of 1.62 was obtained, smaller than the theoretical value of 1.833 for 9 degrees of freedom and $\alpha=0.05$ (two tails), indicating that the method is accurate.

\subsubsection{Detection and Quantitation Limits}

The value of LOD was found to be $0.001432 \mu \mathrm{g} / \mathrm{mL}$ and LOQ was $0.004339 \mu \mathrm{g} / \mathrm{mL}$. 


\subsubsection{System Suitability Tests}

The system suitability test was developed for the routine application of the assay method, ensuring the adequacy of the proposed HPLC method. The precision test and the tailing factor studies show good injection repeatability and peak symmetry, respectively (Table 2). The values of capacity factor $(k \geq 2)$ indicate that the peak is well resolved with respect to the void volume. The theoretical plate numbers $(N \geq 2000)$ reflect good column efficiency. The proposed method met these requirements within the accepted limits [5].

Table 2. HPLC system suitability tests for vanillyl butyl ether.

\begin{tabular}{cc}
\hline Test & Values \\
\hline Retention time $(\mathrm{min})$ & 13.719 \\
Injection repeatability & 0.67 \\
Tailing factor & 0.713 \\
Capacity factor $(k)$ & 11.703 \\
Theoretical plate count $(N)$ & 8244 \\
\hline
\end{tabular}

\subsubsection{Analysis of Vanillyl Butyl Ether in Marketed Preparations}

The developed and validated method was applied to the determination of vanillyl butyl ether in a cosmetic product. A single sharp peak of vanillyl butyl ether was observed at the corresponding retention time when a suitably diluted solution of the tiger balm preparation was injected following extraction (Figure 1). No interaction was observed between vanillyl butyl ether and the excipients and perfumes present in the formulae. The vanillyl butyl ether content was determined by applying the formula obtained in the calibration curve, with RSD values of less than $1 \%$ indicating the suitability of this method for routine analysis of vanillyl butyl ether in cosmetic preparations (Table 3).

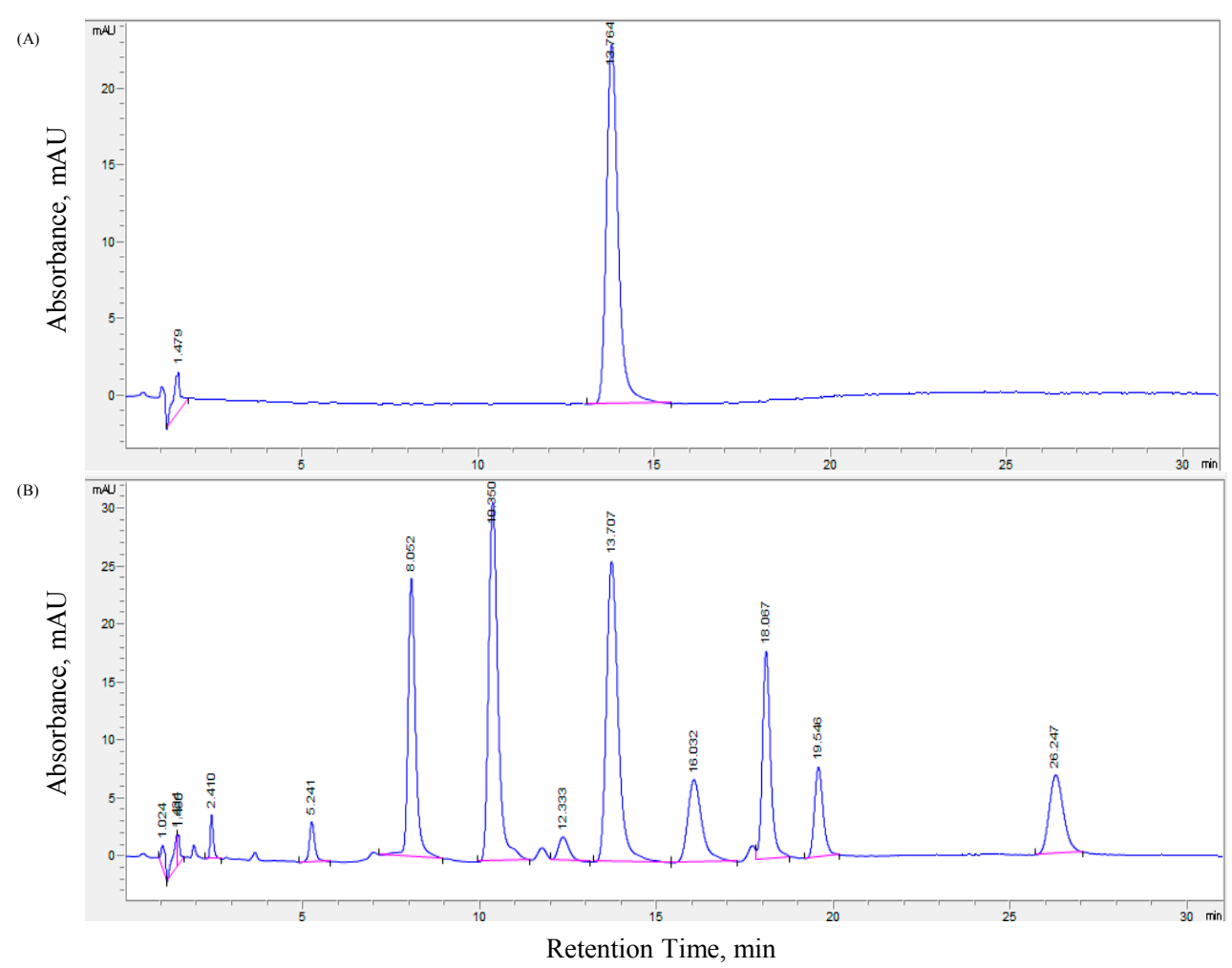

Figure 1. (A) Chromatogram of standard vanillyl butyl ether; (B) Typical chromatogram of vanillyl butyl ether in tiger balm eluted at $13.728 \mathrm{~min}$. 
Table 3. Concentration of vanillyl butyl ether in commercial cosmetic product.

\begin{tabular}{ccc}
\hline Product & Concentration $(\mu \mathrm{g} / \mathrm{mL}) \pm \mathrm{SD}$ & $\% \mathrm{RSD}$ \\
\hline Balsamo oriental & $76.24 \pm 0.51$ & 0.67 \\
\hline
\end{tabular}

\section{Conclusions}

A reversed phase HPLC assay method with UV spectrophotometric detection on a C-18 analytical column was successfully developed for the determination of vanillyl butyl ether. The described analytical procedure has been proved to be accurate, precise and suitable for the determination of vanillyl butyl ether in cosmetic products. The method can be used for the routine quality control analysis of compounds in cosmetic products containing vanillyl butyl ether.

Acknowledgments: Francisco Ríos acknowledges the support from the Spanish Ministry of Economy, Industry and Competitiveness within the postdoctoral grant "Ayudas para contratos Torres Quevedo" (PTQ-15-07879).

Author Contributions: J.M., A.A. and F.T. conceived and designed the experiments; G.M. and A.A. performed the experiments; F.R., A.A. and J.M. analyzed the data; G.M and F.T. contributed reagents/materials/analysis tools; A.A and F.R wrote the paper.

Conflicts of Interest: The authors declare no conflict of interest.

\section{References}

1. Turner, P.; Volan, G.; Wiseman, H. Drugs Handbook 1996-97; Springer: Berlin/Heidelberg, Germany, 1997.

2. Chen, L.-C.; Wu, S.-J.; Huang, C. Vanillyl butyl ether to topically induce blood cell flux, warming sensation. Cosmet. Toilet. 2010, 125, 34-39.

3. Ashton Acton, Q. Benzyl Compounds-Advances in Research and Application: 2013 Edition; ScholarlyEditions: Atlanta, GA, USA, 2013.

4. Barel, A.O.; Paye, M.; Maibach, H.I. Handbook of Cosmetic Science and Technology, Third Edition; Informa Healthcare Publishers: New York, NY, USA, 2009.

5. US Pharmacopoeia (USP) 32, Chromatography, Section 621; United States Pharmacopeal Convention: Rockville, MD, USA, 2009; p. 1776.

(c) 2017 by the authors; licensee MDPI, Basel, Switzerland. This article is an open access article distributed under the terms and conditions of the Creative Commons Attribution (CC BY) license (http:/ / creativecommons.org/licenses/by/4.0/). 